\title{
ROBOTIC FLIGHT SYSTEMS AND APPLICATIONS
}

\author{
*1Dilehan Avşar and ${ }^{2}$ Gökhan Avşar \\ ${ }^{* 1}$ Vocational High School of Yüksekova, Department of Organic Farming Hakkari University, Turkey \\ ${ }^{2}$ Phd Student of Agricultural Machinery and Technologies Engineering Department, Faculty of Agriculture Ankara \\ University, Turkey
}

\begin{abstract}
Drone technology is becoming more and more popular in our lives. Drone technology; industry, art, agricultural production, and many other areas are heavily used. With the system called Agricultural Unmanned Aerial Vehicle (DRONE), at least 10 percent efficiency is expected to be achieved every year in agricultural land. In practice, agricultural lands are examined and the places where intervention is needed for soil health are determined. With the multispectral camera on it, the appearance of the land is examined and a soil map is taken and it is determined that the area of 100 hectares is photographed in 30 minutes. As a result, soil structure is analyzed, chlorophyll map is created, plant health is examined and weeds are detected. Irrigation is also checked for difficulty. After the work, it is ensured that the producer can benefit from the soil in the most efficient way.

In this study, you will be informed about the types of drone types used for agricultural purposes, whether you need to register a drone owner's vehicle, selected applications and what you can see in the images. With the help of a detailed literature, those experienced in different countries and in particular for agriculture to be evaluated will be determined case for Turkey.
\end{abstract}

Key words: Robotic flight, drone use in agriculture, drone types for agricultural purposes, unmanned aerial vehicles

\section{INTRODUCTION}

The aerial drone is a unique remote sensing platform that allows real-time collection of remote sensing data. Over the past few years, the press has emphasized how much unmanned aerial systems (UAS) will be used to improve farming.

Drone technology has been used in agriculture since 1980 for the first time, starting to use with the Japanese fertilizing. Sustainable agriculture, a concept that best reflects drone potential and sheds light on the future of the agri-food system, and drone's are key sources of the ultimate goal to achieve for truly sustainable agriculture. The positive impact of the drone on innovative agriculture is evident in the course of the land and insemination preparations. Advanced drone

*Corresponding author: Address: Vocational High School of Yüksekova, Department of Organic Farming Hakkari University, Hakkari TURKEY. E-mail address: dilehanavsar@hakkari.edu.tr 
technology is leading to the realization of 3D maps, the analysis of soil and the development of seeding. The drone also successfully manages the seeding of the soil. This new technique allows seeds and nutrients to be planted directly into the soil and placed at exactly the desired location, unlike conventional seeding methods. This system allows farmers to plant $75 \%$ of their crops, reduces sowing costs by $85 \%$ and boosts sustainability. In addition, thanks to the advanced imaging techniques and special thermal sensors used, it is easy to determine which part of the field needs water and where it needs to be reinforced with nutritious items. In the stage of planting the seeds of the sowing, the traditional methods may be insufficient to keep the soil under control. Satellite images are not always available, and even if images are removed, it does not give as much detail as to be a solution to the problem of the farmer. That's where drones go in. With practical technology, the drone can map out the land several times a day, regularly provides a comprehensive information flow, and all these data makes it easy to calculate the best time to start the damage.

Another important factor for sustainable agriculture is the amount of pesticides used. At this stage, drone's provide the most effective and environmentally-friendly solutions, especially for pesticide applications, thanks to the ability to determine the most accurate location of the soil for which the pesticide is needed. Thus, the use of unnecessary pesticides is avoided, adding a plus to the success of sustainable agriculture.

\section{ABOUT ROBOFLIGHT SYSTEMS}

RoboFlight Systems assists our clients in acquiring, processing, analyzing, and managing remotely sensed data in order to make intelligent precision agriculture management decisions.

Relatively cheap drones with advanced sensors and imaging capabilities are giving farmers new ways to increase yields and reduce crop damage.

Can I Fly a Drone Today?

- The aircraft is flown strictly for hobby or recreational use

- Fly below 400 feet and remain clear of surrounding obstacles

- Keep the aircraft within visual line of sight at all times

- Remain well clear of and do not interfere with manned aircraft operations

- Don't fly within 5 miles of an airport unless you contact the airport and control tower before flying

- Don't fly near people or stadiums

- Don't fly an aircraft that weighs more than $55 \mathrm{lbs}$.

- Don't be careless or reckless with your unmanned aircraft-you could be fined for endangering people or other aircraft.

*Corresponding author: Address: Vocational High School of Yüksekova, Department of Organic Farming Hakkari University, Hakkari TURKEY. E-mail address: dilehanavsar@hakkari.edu.tr 
Possible Jobs for UAS:

- Agricultural monitoring (crops \& animals)

- Weather monitoring

- Disaster assessment \& management (tornadoes, floods, wildfires, earthquakes)

- Tower, bridge, rail and power line surveys

- Hazardous site evaluation (chemical, nuclear, etc.)

- Law enforcement (locate threats, document site for evidence)

- Environmental monitoring \& research

- Aerial imaging/mapping (real estate)

- Oil and gas exploration

- Telecommunications (news coverage, sporting events, moviemaking)

- Freight transport/package delivery

- Agri-tourism

- Entertainment (unique photography, remote dog walking)

Most Common Uses by Farmers;

- "Directed scouting" of animals and crops, which involves "ground-truthing" what you observe from air

- Crop condition (growth, insects and diseases)

- Cattle counts, rustler monitoring

\subsection{Economic Impact}

More $\$ 13.6$ billion in the first three years

-\$82.1 billion between 2015 and 2025

-More than 34,000 manufacturing jobs

-More than 70,000 new jobs in the first three years

-An anticipated 103,776 new jobs by 2025

-Tax revenue to the states exceeding $\$ 482$ million in the first 11 years following integration (2015-2025)

-Every year that integration is delayed, the United States loses more than $\$ 10$ billion or $\$ 27.6$ million per day that UAS are not integrated into the NAS.

-There are 10 times more sUAS applications in agriculture than any other area $80 \%$ of the economic impacts of sUAS will be in agriculture.

\subsection{Possibilities with Other Sensors}

- Thermal (infrared)

- Livestock detection, sick animals

- Fires, farm safety

*Corresponding author: Address: Vocational High School of Yüksekova, Department of Organic Farming Hakkari University, Hakkari TURKEY. E-mail address: dilehanavsar@hakkari.edu.tr 
- Water temperature, source identification

- Multispectral

- Crop growth, plant identification

- LiDAR (Light Detection And Ranging)

- Measuring plant height, 3-D terrain mapping

\subsection{Unmanned Aircraft Systems}

Multirotor systems are appropriate for small scale and research operations under 50 acres. The Fixed Wing can cover over 1000 acres at 1.0 inch resolution a day. Manned Aircraft; has been committed to collecting and processing quality remotely-sensed data, whether it could be from unmanned aircraft, manned aircraft, or satellites. It has platform agnostic. DJI S800 with gimbals and camera mounted. Disadvantage is one cannot cover larger areas (10 to 50 acres), An Advantage is you can have gimbals and carry heavier payload.

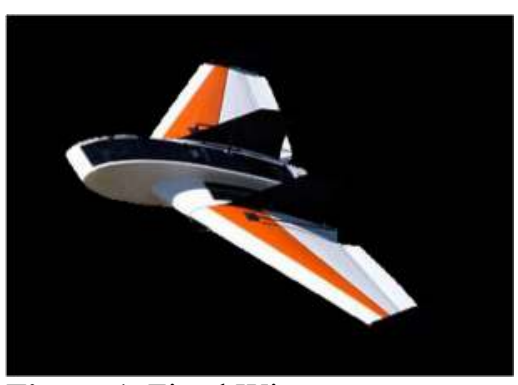

Figure 1. Fixed Wing

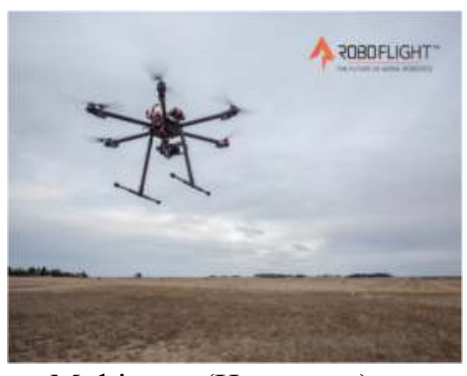

Multirotor (Hexcopter)

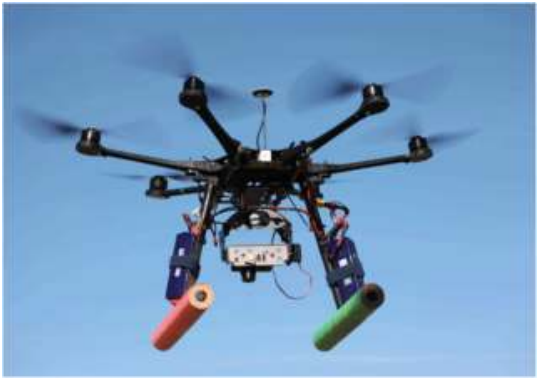

DJI S800

\section{AGRICULTURAL APPLICATIONS IN TURKEY}

The drone's ability to safely and quickly survey farmland and assist in precision control over chemical and fertilize application rates can greatly increase farm industry profitability. Farmers, environmentalists and regulatory agencies can use drones for real-time analysis of farm areas, coastal areas and various other land areas to study a wide range of data points from tracking crop treatments to catalogin regional and coastal topography as part of preservation efforts. Agricultural survey drones can monitor land use and take air samples to help researchers gather valuable data, which can be used for various precision agriculture applications. Agronomic uses include capturing NDVI maps indicating plant health and biomass which may assist farmers in making agronomic decisions relating to input placement.

\subsection{Tomatoes Aerial Image Capture}

*Corresponding author: Address: Vocational High School of Yüksekova, Department of Organic Farming Hakkari University, Hakkari TURKEY. E-mail address: dilehanavsar@hakkari.edu.tr 


\section{Crop Density Assessment}

Within the accuracy assessment areas: 2,335 plants delineated $10.5 \%$ less than capacity.
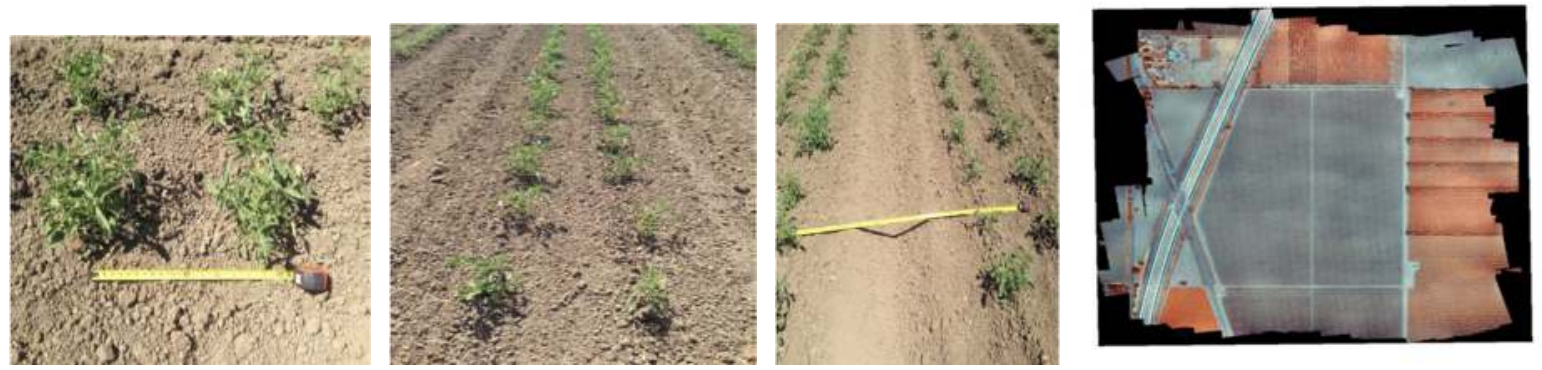

Figure 2. Aerial Image Capture and Color Infrared Orthomosaic

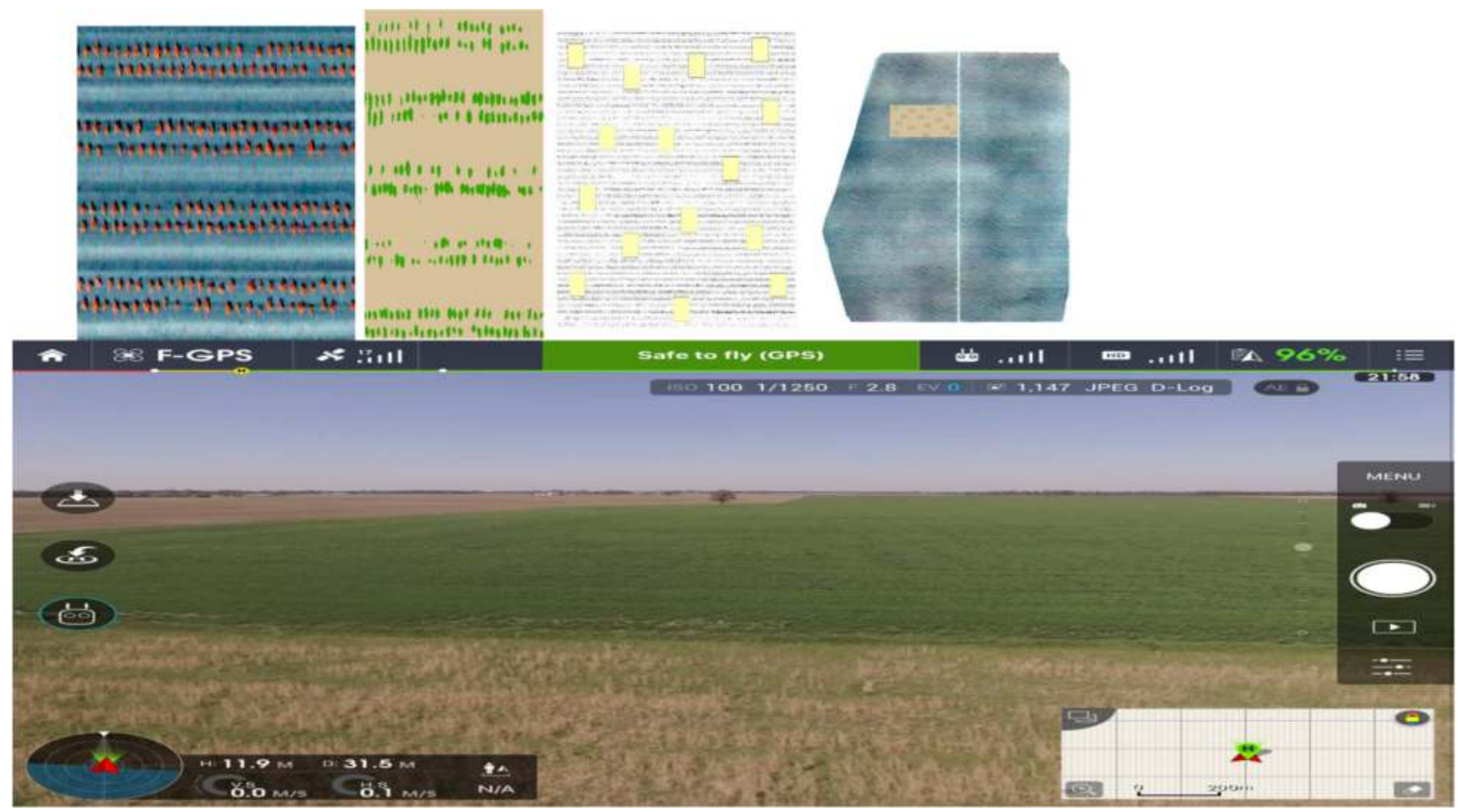

Figure 3. Color Infrared Image showing individual tomato plants

\subsection{Crop Yield Potential}

This is far more complex than all the other use cases, but is the most often cited for drones. These assessments involve acquiring NDVI images, thermal or stereoscopic images from sensors mounted on a UAS and then processing and evaluating the data for potential use in VRT. A strong correlation has been demonstrated between yields and NDVI at certain crop growth stages, as described in the research. NDVI allows agronomists and producers to identify problem areas and make timely decisions. Scouting maps can be requested at key dates as guidance for field *Corresponding author: Address: Vocational High School of Yüksekova, Department of Organic Farming Hakkari University, Hakkari TURKEY. E-mail address: dilehanavsar@hakkari.edu.tr 
visits. NDVI-based scout maps show variations in the field, so users know where to look in the field to determine where corrective or preventative measures are needed. Users can plan their field visit locations, take it to their GPS or a printable pdf report, and accurately evaluate the reasons for infield variability. To be clear, much of the workflow and data processing happens outside of actual drone use and is much more complex than is shown in Figure 4 above. This workflow applies to the most common varieties of row crops (wheat, corn, soya bean, etc.). SenseFly has outlined a complete step-by-step guide that explains how drones fit within the precision crop scouting workflow.

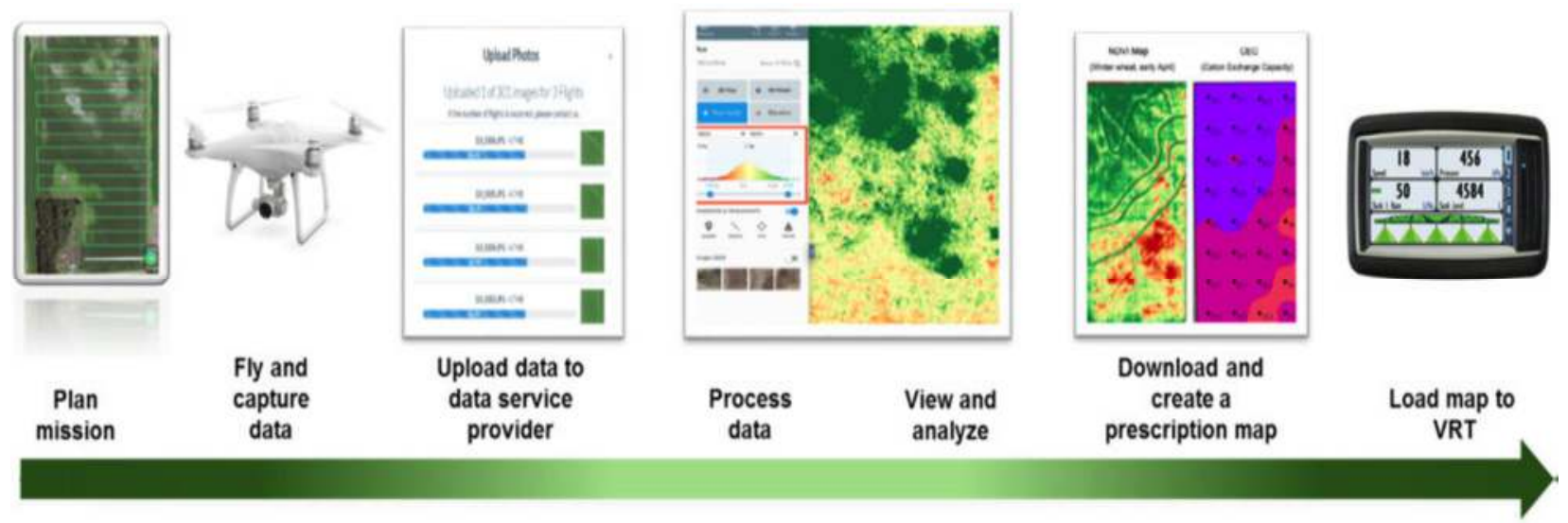

Figure 4. Advanced Crop Scouting Workflow

\section{WHAT'S NEXT FOR DRONES IN AGRICULTURE}

With the total value of our nation's crops estimated at $\$ 212$ billion per year, even a modest improvement in yield would have a substantial aggregate economic impact. However, it's not yet clear how a unmanned aerial systems (UAS) can deliver more usable information to a farmer or provide a cost benefit over the existing image solutions available to them today. What seems to be missing from today's drone data service providers is the expertise to interpret the data, verify it with what is actually happening in the field (aka "ground truthing"), and recommend a course of action. Services that deliver aerial imaging can provide the data, but someone needs to invest the time, money, skills, and software to get actionable insight from it. Right now, it appears that's not being done well by the dealers who already offer imaging from satellites and manned aircraft. What's not clear is how that's going to change when they start offering imagery from drones. Despite those issues, the technology used in agriculture drones and aerial imaging processing is progressing rapidly-more rapidly and at lower costs than satellite or manned aircraft. For example, the four major players of drone image sensors today, MicaSense, Parrot, Slantrange, and Tetracam, are working to tackle the concerns over the lack of calibrated imagery from drones. Calibrated imagery provides the added value of monitoring crop changes over time. They are also working to solve the issue of images taken with cloud cover and differing sun positions. In a perfect world, data would come from a sensor with RBG, various light bands, and an ambient light sensor. Keep your eye on this space for more innovations 


\section{Results}

This research shows that lightweight aerial drones can regularly monitor agricultural regions as part of a systematic farmland management and control system. Unlike manned aircraft, lightweight drones require less fuel, and maintenance costs are much lower.

Lightweight drone aircraft are highly mobile and capable of being carried close to study areas on foot or by using land vehicles. Survey drones can easily be transported into areas whenever the need arises. In addition, the added safety of not putting manned aircraft at risk while also offering no risk to those on the ground in comparison to manned aircraft, make lightweight drone aircraft a favorable choice for agricultural land management efforts.

Aerial drone systems have a many uses. Robotic drone aircraft can be the foundation of an advanced remote-sensing- based agricultural control system, which can revolutionize the industry. In addition, these autonomous systems can also be used as part of environmental and coastal preservation efforts.

Farmers, environmentalists and regulatory agencies can use drones for real-time analysis of farm areas, coastal areas and various other land areas to study a wide range of data points from tracking crop treatments to cataloging regional and coastal topography as part of preservation efforts.

There is information in your pastures and fields that remote sensing can help you extract and use. Other forms of remote sensing (airplane, satellite) are expensive and frustrating. UAS puts the control in your hands either directly or through your adviser $[1,2,3,4,5,6]$.

\section{REFERENCES}

[1] https://www.barillacfn.com/en/magazine/food-and-society/drones-technology-for-the-benefit-ofsustainable-agriculture//Erişim tarihi: 13.08.2018

[2] Association for Unmanned Vehicle Systems International (AUVSI)

[3] extension.missouri.edu/webster

[4] Utah Water Research Laboratory, Utah State University alfonso.torres@usu.edu

[5] Statistics per Association of Unmanned Vehicle Systems International (AUVSI) 2013 Report

[6] Research \& Technology Development, kevin@roboflight.com 